\title{
A Message from the Director
}

\author{
Sidney A. McNairy Jr., Ph.D., D.Sc.
}

Director, Division of Research Infrastructure, National Center for Research Resources, National Institutes of Health, Department of Health and Human Services

Received: 21 September 2002 / Published: 30 September 2002

The National Institutes of Health (NIH), located in Bethesda, Maryland, a suburb of Washington, D.C., is one of the agencies of the Public Health Services that, in turn, is part of the U.S. Department of Health and Human Services. Now comprised of 27 separate components, NIH has grown from a total operating budget of about a total of about $\$ 300$ in 1887 , to nearly $\$ 23.4$ billion for 2002 . NIH is the world's premier medical research organization, the steward of medical and behavioral research for the Nation. The NIH mission is science in pursuit of fundamental knowledge about the nature and behavior of living systems and the application of that knowledge to extend healthy life and reduce the burdens of illness and disability. The National Center for Research Resources (NCRR) is one of the component organizations of the NIH. The NCRR serves as a "catalyst for discovery" by creating and providing critical research technologies and shared resources. This infrastructure underpins biomedical research and enables advances that improve the health of our nation's citizens. NCRR funding provides biomedical researchers with access to diverse instrumentation, technologies, basic and clinical research facilities, animal models, genetic stocks, biomaterials, and other resources that enable scientific advances in biomedicine, and lead to the development of life-saving drugs, devices, and therapies.

Within NCRR, the Division of Research Infrastructure (DRI) expands the nation's capacity for the conduct of biomedical and behavioral research by developing the research infrastructure at minority institutions; improving biomedical and behavioral research facilities through matching grants for construction and renovation of animal facilities; and increasing research competitiveness of faculty at institutions from states with limited NIH support. These objectives are achieved by providing support on a competitive basis through the following DRI programs: 1) the Research Centers in Minority Institutions (RCMI) Program, the Animal Facilities Improvement Program, the Research Facilities Improvement Program, and the Institutional Development Award (IDeA) Program. 
The RCMI Program was initiated in 1985. The authorizing legislation for the program called attention to the Department of Health and Human Services Heckler's (DHHS) Secretary's Task Force on Black and Minority Health. In this report, the Task Force identified six causes of death that accounted for more than 80 percent of the mortality in African Americans, Hispanic Americans, Native Americans and Asian Pacific Islanders. These included: a variety of cancers; diabetes; homicide, suicide and unintentional injuries; infant mortality and low birth weight; chemical dependence; cardiovascular disease; and cerebrovascular disease. In 1996, the scope of the RCMI Program was expanded to facilitate the participation of the seven medical schools with RCMI Programs, in clinical research through the development of the RCMI Clinical Research Infrastructure Initiative (RCRII). Through the expansion of the RCMI Program, as well as increased funding from the NIH overall, there has been a significant increase in the participation of scientists at RCMI-eligible institutions in biomedical research. The RCMI Program currently provides support to nineteen institutions including seven medical schools, two colleges of pharmacy, nine graduate schools, and one school of veterinary medicine. These institutions are located in ten states, the District of Columbia, and Puerto Rico. The many scientific advances that have emerged from the RCMI grantee community are further evidence that this community must continue to join in the fight against cancer, cardiovascular diseases and other disabling conditions.

The RCMI Program provided support for the 2002 Spring Symposium organized and hosted by Jackson State University in Jackson, MS. The symposium focused on "Recent Advances in Environmental Health Research: Health Disparities, Toxicology and Carcinogenesis". Collaborations between NCRR and various NIH Institutes and Centers, as well as the collaborations that the RCMI grantee community has established with the broader scientific community have been crucial to bringing to fruition symposia such as this. A review of the manuscripts in this publication underscores the value of faculty at RCMI grantee institutions having spent much time and effort in pursuing relevant research questions. These papers emerged from the 113 abstracts that were presented during the 2002 RCMI Spring Symposium and include examples of scientific advancements in the areas of: 1) Biomarkers and Signal Transduction in Cancer; 2) Environmental Toxicology and Carcinogenesis; 3) Environmental Risk Factors and Cancer; 4) Health Risk Assessment and Management of Environmental Contaminants; 5) Emerging Topics in Computational Biology; 6) New Frontiers in Genetic Toxicology; and 7) Health Disparities and Cancer. It is significant to note that Dr. Kenneth Olden, Director of the National Environmental Health Sciences, and Director of the National Toxicology Program at NIH, gave a distinguished lecture entitled "The Environmental Genome Project-A More Rational Approach to Gauging Environmental Threats". This lecture focused on future challenges and excitement in biomedical research, especially as it relates to the role of geneenvironment interactions in disease development and health disparities.

As we advance into the new century, it is clear that the RCMI grantee community has a critically important role to play in addressing the health needs of all people both within the United States as well 
as the world over. The research that is reported in this volume, is one of many examples of the capacity of these institutions to play a prominent role in addressing the important research questions that will help to unravel the mysteries surrounding the actions of physical, chemical and biological agents on human health.

(C) 2002 by MDPI (http://www.mdpi.org), Basel, Switzerland. 